\title{
0 efeito educacional em Foucault. 0 governamento, uma questão pedagógica?
}

\author{
Dora Lilia Marín-Díaz*, Carlos Ernesto Noguera-Ramírez * * \\ Para Alfredo Veiga-Neto, professor.
}

\section{Resumo}

O artigo retoma a tese de Hoskin (1993b) segundo a qual o trabalho arqueológico e genealógico de Foucault girou ao redor de problemas educacionais ainda que ele não fosse ciente dessa questão. Além de ratificar ou rejeitar essa afirmação, o texto considera que a noção de "governamentalidade", construída nos seus últimos cursos no Collège de France pode ser mais bem compreendida se considerada a partir da análise das práticas pedagógicas, pois estas constituem práticas privilegiadas de condução da conduta própria e a dos outros. Para suportar * Instituto para la Investigación Educativa y el Desarrollo Pedagógico (IDEP), Alcaldía Mayor de Bogotá, D.C., Colombia. azulesdora@hotmail.com

** Universidad

Pedagógica Nacional, Bogotá, D.C., Colombia. cnoguera@pedagogica.edu.co essa afirmação, mostraremos, com alguns exemplos derivados de pesquisas prévias, a centralidade das práticas pedagógicas nos modos de praticar a condução da vida na chamada Modernidade e sua relevância nas formas de condução contemporâneas.

\section{Palavras-chave}

Foucault, educação, governamentalidade, práticas pedagógicas. 


\title{
The Educational Effect in Foucault. Is the Government a Pedagogical Issue?
}

\begin{abstract}
The article incorporates the thesis of Hoskin (1993) that the archaeological and genealogical work of Foucault spun around educational issues although he had not been aware of it. Before we ratify or reject this claim, we consider that the notion of "governmentality", built in his last lectures at the Collège de France, can be better understood if it is taken as part of an analysis of pedagogical practices as they constitute privileged conduct practices of self and of the others. To support this claim, we will showthrough some examples derived from previous research the centrality of pedagogical practices in the modalities of the government of life in the so-called Modernity and its relevance in contemporary forms of government.
\end{abstract}

Keywords Foucault, education, governmentality, pedagogic practices. 


\section{Introdução}

A intenção deste artigo é resgatar e atualizar a tese proposta, quase 25 anos atrás, pelo professor inglês Hoskin (1993b, a edição em inglês data de 1990), segundo quem, durante todo seu trabalho, Foucault realizou uma análise pedagógica, embora pensasse que se referia ao poder, ao saber, e - convém agregar hoje -, ao governamento. Apesar de a tese ser instigante, ou arriscada e polêmica, ela não mereceu maiores comentários no campo acadêmico. Mas hoje, 30 após a morte do filósofo e 6 anos depois da publicação (em espanhol e português) dos seus cursos de 1978 e 1979, vale a pena revisar aquela afirmação que Hoskin fez na coletânea compilada por Ball (1990), Foucault and Education.

Naquele texto, Hoskin chama Foucault de "criptoteórico" da Educação e assinala que, tanto em As palavras e as coisas quanto em Vigiar e punir, o filósofo trata assuntos próprios da Educação. Na primeira obra, a partir de uma perspectiva arqueológica, o filósofo enfrenta, no dizer de Hoskin, um problema da história da Educação, pois, ao analisar a transformação ou a passagem de alguns campos de saber (gramática geral, história natural, análise das riquezas) para outros (filologia, biologia e economia política), algumas questões poderiam ser respondidas; dentre elas, a seguinte: como uma série de gerações que escreveram e construíram determinados modos de saber (a episteme representativa de Foucault) transmitiu para outra série de gerações que escreveu de maneira muito diferente? Evidentemente, responde Hoskin, aprendendo, e esta os escreveu em outro registro. Mas como aprenderam a fazer isso os mais jovens?, continua o autor. Fazendo-o sob a tutela dos mais velhos. Desse modo, conclui, Foucault nos legou um mistério da história da Educação (Hoskin, 1993b, p. 33-34).

Uma solução fácil para explicar essa mudança seria recorrer às razões externas sociais, políticas ou econômicas - como a Revolução Francesa ou Industrial, por exemplo, ou explicações individualistas, como o aparecimento de um novo olhar, proveniente de pessoas geniais. Mas, esse não é o caso de Foucault. A chave do enigma - como os jovens, ensinados no antigo registro, sob a antiga episteme, conseguem aprender a aprender de um novo jeito e produzir, assim, as modernas disciplinas do saber (Hoskin, 1993b) - está justamente na disciplina, palavra proveniente do campo educacional ${ }^{1}$, que está, intimamente, vinculada ao trabalho de Foucault. Para Hoskin, a disciplina é um termo "maravilhosamente flexível” (1993b, p.

1. Para uma ampliação da proveniência desse termo do vocabulário pedagógico medieval, ver: NogueraRamírez (2011). 
34), pois propõe uma trapaça: serve para falar tanto do saber quanto do poder. A disciplina, na linguagem pedagógica medieval, refere-se, ao mesmo tempo, ao fato de apresentar a doutrina (os ensinamentos), de receber esses ensinamentos ou apropriar-se deles, resultando daí o aprender. (Marrou apud Noguera-Ramírez, 2011).

Na segunda obra, Hoskin avança na sua pesquisa na tentativa de desmascarar o "criptopedagogo" e passa a revisar outro dos problemas centrais trabalhados pelo filósofo: o "exame". Nela, além das análises óbvias sobre a disciplina, o centro de interesse do pesquisador passa a ser essa microtecnologia particular e especial que "mistura o desdobramento da força e o estabelecimento da verdade: o exame" (Hoskin, 1993b, p. 35). Segundo Hoskin, o exame é a técnica mais obviamente educacional e, como afirma Foucault, “a superposição das relações de poder e de saber assumem no exame seu máximo esplendor” (apud Hoskin, 1993b, p. 35). Essa dupla condição do exame constitui sua potência, sua capacidade para transformar relações de poder em saber e saber em relações de poder. 0 próprio Foucault (2001, p. 191192) assinala que "assim como o procedimento do exame hospitalário tem permitido o desbloqueio epistemológico da medicina, a época da escola 'examinadora' tem marcado o começo de uma pedagogia que funciona como ciência”. Sobre esse aspecto, Hoskin salienta o fato de ser esse instrumento pedagógico um elemento fundamental para a constituição da medicina clínica, segundo as análises do filósofo na sua arqueologia da mirada médica. Foi a reforma da Pedagogia, no fim do século XVIII, que possibilitou a passagem da forma de ensinar e dizer para a forma de aprender e ver (Foucault, 1985), transformando o olhar médico e permitindo uma nova disposição epistemológica. Para Hoskin (1993b), a moderna profissão médica só se originou quando os estudantes tiveram que aprender de uma nova maneira, submetendo-se a exames, por meio dos quais eram classificados, aprovados e licenciados ou, caso contrário, reprovados.

Mas aqui não termina o assunto. Essa “oculta obsessão” (Hoskin, 1993b, p. 43), na obra de Foucault, pelo exame - e, portanto, pela Educação - não é exclusiva do seu período arqueológico e genealógico, nos seus últimos trabalhos sobre a subjetividade e a formação do eu "ainda fala - mais ainda em realidade -, sobre o campo educativo e pedagógico. Desde o início de L'usage des plaisirs, está claro que as relações que o eu tem de descobrir por si mesmo têm uma conexão pedagógica" (Hoskin, 1993b, p. 41). No segundo volume da sua História da Sexualidade - Le souci de soia questão se mantém, ao expor as práticas-chave implicadas no cultivo de si, que 
se mostra "como uma prática pedagógica desenvolvida sobre o eu na qual o sujeito aprende a interiorizar a voz pedagógica que recomenda a arte adequada do bom viver dentro de cada um até converter-se em si mesmo" (Hoskin, 1993b, p. 41). Dessa forma, Hoskin chega ao fim da sua pesquisa, considerando que sua empreitada para desmascarar o "criptopedagogo" Foucault tem sido bem-sucedida e concluindo que, em distintas épocas, "o educacional” pode funcionar como o hífen que permite a relação poder-saber:

Graças a Walzer, percebemos que a operação do poder-saber requer um terceiro termo: atua quiçá mediante o exame, a inquisitio, a disciplina o a Paidéia. A questão fascinante e mistério permanente é: em estrito sensu, acaso esse terceiro termo pode não ser educativo? Cabe alguma conclusão que não seja a de que Foucault foi um critopedagogo? (Hoskin, 1993b, p. 56 , grifos do autor).

Além da veracidade ou não, da pertinência ou não da tese de Hoskin, aquilo que gostaríamos de salientar aqui é a indiscutível proximidade entre os objetos de análise do filósofo e determinadas questões pedagógicas que, embora não se reduzam, como pensava Hoskin, à disciplina e ao exame, aparecem como elementos articuladores da relação saber-poder. Não é nosso interesse contribuir na consideração de Foucault como "criptopedagogo"; não pretendemos colocar o pensador do lado do campo da Educação e aproveitar essa condição para dar destaque à Pedagogia, considerada disciplina menor ou subdisciplina, como salienta Hoskin (1993a) em outro dos seus trabalhos. Ainda que seja uma realidade que a Pedagogia ocupa um lugar secundário dentro das ciências sociais e humanas; que o seu caráter científico seja questionado pelas outras ciências; que, no máximo, seja considerada como disciplina aplicada das verdadeiras ciências sociais e humanas, também é uma realidade que, a partir de novos olhares, o seu lugar de destaque na constituição da nossa modernidade é cada vez mais evidente e que, como afirma Hoskin (1993b, p. 33), "na verdade, Foucault descobriu algo muito simples (ainda que muito raro, embora): o caráter central da educação na construção da modernidade".

Neste artigo, a nossa proposta é continuar a assinalar e a exemplificar a centralidade das práticas pedagógicas nas formas de praticar a condução da vida na Modernidade e sua relevância nos modos de condução contemporâneos. Isso a partir 
de algumas reflexões, resultado de dois estudos que realizamos entre 2006 e 2012 , nos quais, fazendo uso da noção de "governamento" (gouvernment) elaborada por Foucault, no seu curso de 1978, Segurança, Território, População, mostramos que, entre os séculos XVI e XX, nas sociedades ocidentais, emergiram três modos de pensar e praticar a Educação, vinculados a três formas de subjetividade diferenciáveis, que vão desde as primeiras formas de ser sujeitos modernos (eus centrados e funcionais para os nascentes Estados e Igrejas modernas) até as contemporâneas formas de capitais humanos adaptáveis e em permanente procura pelo sucesso e pela felicidade.

Tal empresa intelectual se articula com um projeto de grande fôlego intelectual, levado adiante pelo filósofo alemão, Peter Sloterdijk (2012, p. 427, grifos do autor), que afirma:

Só será possível fazer justiça à Idade Moderna se é associada com uma mudança mental, moral e técnica até agora nunca apresentada adequadamente: a existência dos tempos modernos apresenta signos de um exercício global de fitness onde aquilo que se chamava de "diferenciação ética", o chamado intensivo para a elevação da vida - só iniciada na época pré-moderna por uma minoria - se transformaria em um imperativo metanoético dirigido a todos e para o qual se dão múltiplas respostas. Seus mediadores seriam, em primeira linha, o Estado moderno e a escola adequada a ele, com o apoio enérgico de ministros de todas as confissões.

A época moderna inicia, segundo Sloterdijk, no momento em que o imperativo de transformação da vida deixa de ser assunto de uma elite e passa a ser considerada como uma necessidade de todos e de cada um. Segundo Comenius - educador amplamente comentado por Sloterdijk e apresentado como o iniciador do movimento "Mestres sem fronteiras" e o incentivador da primeira "Internacional da Educação" é preciso "ensinar tudo a todos" para a salvação da humanidade, devemos aprender ao longo da vida toda, desde o berço até o túmulo. Esse mesmo entendimento levou Hoskin (1993a, p. 272) a propor uma reviravolta na forma de compreender a Educação: “a educação, longe de ser subordinada, é superordinada; e que uma compreensão da educação e seu poder é a única maneira de entender a gênese da disciplinariedade e o subsequente crescimento aparentemente inexorável do seu poder".

Pouco importa, então, se Foucault foi ou não um criptopedagogo. Aquilo que nos 
interessa aqui é mostrar que, além do assinalado por Hoskin para a disciplina e o exame e para o caso dos trabalhos arqueológicos e genealógicos, a noção de "governamentalidade" também está intimamente relacionada a assuntos pedagógicos e educacionais. Em outras palavras, diríamos que o que o professor Foucault chamou de governo pode ser compreendido de maneira muito mais aprofundada, se, tomando distância das doutrinas políticas e econômicas, nos aproximarmos dos discursos e das práticas pedagógicas modernas. Trata-se, ao mesmo tempo, de uma precaução metodológica e de uma aposta teórica: precaução metodológica na medida em que não devemos confundir o governo, lido sob a lente da noção "governamentalidade", com assuntos relativos só ao Estado, aos partidos políticos; aposta teórica, se compreendermos melhor a noção de "governamentalidade" e se reconhecermos que as práticas pedagógicas são, fundamentalmente, práticas de governo (de condução da conduta própria e dos outros) e que, desde o século XVI pelo menos, essas práticas têm ocupado um lugar central nos processos de governamento da população.

\section{Sobre a Modernidade como}

\section{a constituição de uma sociedade educativa}

Seguindo a tese de que a Educação se tornou uma das principais artes de governo desde o começo do século XVI, Noguera-Ramírez (2011) assinalou que, em tal processo, é possível perceber três modos de pensar e praticar a Educação e o ensino: o primeiro modo, correspondente aos séculos XVII e XVIII, teve a forma de uma sociedade ensinante ou da Razão de Estado ensinante, em que a Didática se constituiu no saber principal, e o Homo docilis, na forma subjetiva privilegiada: um indivíduo dócil que, na linguagem pedagógica da época, significava o indivíduo capaz de aprender e de ser ensinado. 0 segundo modo, de finais do século XVIII, corresponde a uma forma chamada de Estado educador, momento de emergência do conceito de Educação no vocabulário pedagógico e de expansão da Educação e da instrução pública nos distintos setores e grupos sociais. Nesse modo, os conceitos de Educação e formação (Bildung), por uma parte, e as tradições pedagógicas modernas (as ciências da Educação francófonas, os Estudos do Currículo anglo-saxônicos e a Pedagogia ou Ciência da Educação germânica) por outra, foram as novas formas do saber, sendo o Homo civilis, o indivíduo civilizável, a sua principal figura subjetiva. Finalmente, o terceiro modo, constituído nos alvores do século XX, foi o período de estabelecimento das bases conceituais do que conhecemos como sociedade da aprendizagem e como a 
forma subjetiva do Homo discens: um indivíduo aprendente que já deve não só aprender, mas também, aprender a aprender. Para esse modo de pensar, a Psicopedagogia (francófona e anglo-saxônica) tornou-se a principal forma do saber.

Na perspectiva dessa análise, é possível identificar também que a produção de cada momento e de cada forma de subjetividade esteve articulada com o exercício de um conjunto de práticas de si que, cada vez mais, ocuparam lugares de evidência nos discursos pedagógicos (Marín-Díaz, 2012). Nesse processo de constituição de uma sociedade educativa, as técnicas de si tiveram um lugar de destaque que se expressou na relevância que o indivíduo, sua própria atividade, seus interesses e suas necessidades começaram a ter, bem como na dominância que os discursos sobre a experiência, a aprendizagem e a Educação permanente alcançaram nas discussões educacionais. Isso teve seu correlato na produção de reflexões e materiais destinados ao reconhecimento de uma natureza particular, à identificação de si mesmo e ao estabelecimento de ações concretas para produzir as transformações necessárias para alcançar "a” felicidade.

Assim, os três modos acima referidos constituíram sociedades educativas, na medida em que a arte de educar, seja orientada pelo ensino, pela Educação ou formação, ou pela aprendizagem, foi condição para constituir, realizar e garantir a salvação do indivíduo e da sociedade. Destaca-se, nesse sentido, que, embora a escola tenha, hoje, um lugar privilegiado nesse tipo de sociedade, não é a sua presença que define o seu caráter educativo. Para além da escola, de seus muros e práticas, hoje todos os indivíduos devem estar comprometidos - e em alguma medida, obrigados - a seguir aprendendo em todos os espaços e no decorrer de sua vida toda. Essa era a questão que o próprio Comenius já salientava, quando pensou o mundo todo como uma grande escola - panscolia -, na qual os indivíduos passavam, ao longo da vida, aprendendo em várias "escolas": pré-natal, da infância, da puerícia, da adolescência, da juventude, da idade adulta, da velhice e, até, da morte (Comenius apud Noguera-Ramírez, 2011)².

Como analisamos anteriormente, no primeiro momento, a instrução da população era sinônimo do bom governo que dela fazia o governante. Ela era uma atividade

2. Sloterdijk (2012, p. 446) cita uma passagem do texto de Comenius, Via Lucis, em que o didata morávio fala do mundo como uma "casa disciplinar", pois por toda parte há disciplinas, isto é, "distintas ferramentas necessárias para exortar, aconselhar e impulsionar”. fundamental para atingir a felicidade pública, a salvação de todos e de cada um, e a prosperidade do Reino. Desse modo, a constituição da Razão de Estado encontrou na instrução a chave para asse- 
gurar a manutenção do poder estatal, e a Didática passou a ser considerada como uma arte que respondia a um projeto muito mais amplo, a Pampedia: “assujeitar o indivíduo, desde o berço até o túmulo, a um regime disciplinar baseado num ensinar e aprender constante e por toda a vida" (Marín-Díaz; Noguera-Ramírez, 2012, p. 23).

O indivíduo - Homo docilis - aparece como um animal dotado de uma especial disposição tanto para ser ensinado quanto para aprender. As técnicas disciplinares de instrução, vigilância e controle exercidas sobre ele, para ensiná-lo, fizeram parte do processo de individualização e também foram o fundamento para a ênfase que - depois do século XVIII - alcançaram noções como educação e aprendizagem, ligadas a uma nova forma de governamento, já não de caráter disciplinar, mas “liberal”.

No movimento que significou a passagem da instrução para a aprendizagem, por meio da Educação, vemos serem ressaltadas as técnicas destinadas à própria condução dos desejos, das necessidades e dos interesses que o indivíduo deve fazer, técnicas próprias daquilo que Foucault (2007) chamou de "governamentalidade liberal”. A Educação tornou-se cenário para adquirir esses aprendizados de autocondução da própria vida: "a educação encontra-se mais perto da ação de dirigir ou conduzir que da ação de instruir ou ensinar alguma coisa” (Marín-Díaz; Noguera-Ramírez, 2012, p. 24). Nesse sentido, a Educação focou sua ação na qualidade particular para aprender e na adaptação de um "meio" no qual cada indivíduo - Homo civilis - teria a possibilidade de desenvolver aquilo que traz como parte de sua natureza. São essas as características que Foucault assinala como próprias da era das liberdades, momento de emergência do governamento liberal.

Já, no momento de ênfase na Educação, vemos aparecer, nos discursos pedagógicos, o princípio de atividade (agência) do próprio indivíduo. Ao centrar o foco da atividade educacional mais na aprendizagem do que no ensino, privilegiou-se a ação do indivíduo sobre si mesmo. Aí se potencializou o uso de técnicas autorreflexivas e de autocontrole procedentes da forma de pedagogia pastoral cristã que, séculos antes teria sido configurada (Hunter, 1998). Práticas pedagógicas que, segundo Popkewitz (2008), usaram velhas ferramentas de “condução”, cujos propósitos e prioridades não foram simples cópias das práticas disciplinares, mas a incorporação e a atualização de técnicas na produção de indivíduos governáveis. Nesse sentido, as práticas pastorais são, como assinala Hunter (1998, p. 23, grifos do autor), fonte de uma tecnologia pedagógica específica, como condição para o aparecimento de 
[...] um conjunto especial de disciplinas "espirituais" (de uma prática particular de relacionar-se e governar-se a si mesmo), personificada na relação pastoral entre mestre e aluno. Veremos que é o "jogo do pastor do rebanho", próprio do cristianismo, com sua característica articulação de vigilância e autoescrutínio, obediência e autorregulação, aquilo que continua proporcionando o núcleo da tecnologia moral da escola, muito depois de que foram apagados os seus apoios doutrinais.

Foi, portanto, a irredutibilidade das disciplinas pastorais a princípios teológicos particulares que permitiu às práticas liberar-se da âncora doutrinal que tinham e migrar, tranquilamente, para espaços institucionais diversos, como a escola, o exército, a fábrica, etc. Eis outra forma de descrever esse processo de laicização das práticas de condução pastorais. Em termos gerais, parece que, em torno de práticas autorreflexivas, dois processos se organizaram para a produção das formas de subjetivação modernas: por uma parte, a laicização do poder pastoral, como nomeado por Hunter (1998); por outra parte, a produção do aparato psíquico particular (Elias, 1987; Figueiredo, 1994). Assim, no tempo em que dar forma e reconhecer o "eu" único e diferente foi uma tarefa essencial, um conjunto de gestos paradoxais - de esperança e medo - tornou-se eixo estruturante de muitos discursos educativos nacionalistas e da organização dos Estados. E dispôs a Educação como uma das principais estratégias de governo, tanto do indivíduo quanto do grupo social (Popkewitz, 2008).

Lembramos aqui o fato de considerar, como práticas pedagógicas, o conjunto de práticas em que se produz ou transforma a experiência que os indivíduos têm de si e que thes permite constituir-se em sujeitos. Nesse sentido, tanto as atividades escolares com crianças e adultos quanto aquelas propostas para grupos informais (de terapia espiritual, de cura mental e religiosos), ou mesmo aquelas divulgadas por livros, áudios, vídeos, conferências de motivação, autoajuda, gestão pessoal, etc. são consideradas como práticas pedagógicas, enquanto procuram modificar as relações reflexivas dos sujeitos, enquanto fazem parte de certos aparatos de subjetivação que produzem a pessoa "humana" (Larrosa, 1995).

Acreditamos que as transformações ampliaram as práticas de si, a partir do século XVI no mundo ocidental, e levaram à constituição de certo tipo de indivíduo reflexivo que foi necessário e útil às estratégias de governamento de uma época que, hoje, se chama de Modernidade. Por isso afirmamos, com Hoskin (1993b) e talvez com 
Foucault, que a Modernidade é profundamente educativa. Nesse sentido, é possível analisar, hoje, outras práticas de constituição do sujeito moderno, vinculadas à chamada pedagogia pastoral que precederam, e ainda mais, foram condição de possibilidade das ciências psi desenvolvidas entre os séculos XIX e XX $X^{3}$. Dessa forma, poderíamos afirmar que, se existiu um processo de psicologização da pedagogia no século XIX, esse processo foi precedido por outro: o processo de pedagogização da clássica psicologia das faculdades da alma (Marín-Díaz, 2012) que levou à constituição de uma psicologia considerada científica.

\title{
Práticas de Si e Constituição do Sujeito Aprendente como Exercitante Permanente
}

\begin{abstract}
É a democracia - ou, melhor ainda, o liberalismo que amadureceu no século XIX - que desenvolveu técnicas extremadamente coercitivas que, em certo sentido, se constituíram no contrapeso de uma determinada "liberdade" econômica e social. Os indivíduos, certamente, não poderiam ser "liberados" se não fossem educados de determinada maneira (Foucault, 2003, p. 45 , grifos do autor).
\end{abstract}

O terceiro modo, constituído nos alvores do século XX, foi o período de estabelecimento das bases conceituais do que conhecemos como sociedade da aprendizagem e como forma de subjetivação que qualifica o Homo discens (Marín-Díaz; Noguera-Ramírez, 2011): um sujeito aprendente que já não só deve aprender, mas aprender a aprender. Na base desse modo de pensar está um novo campo disciplinar, a Psicopedagogia e suas vertentes francófona e anglo-saxônica.

Isso nos leva a pensar, então, quais foram as formas que adotaram as relações consigo, num tempo em que se consolidaram as estratégias de governo liberais e, com elas, a difusão ampla e massiva de práticas educativas, além da própria escola. Seguindo essa ideia, é importante reconhecer os modos que determinadas práticas, como a confissão e a direção de consciência, adquiriram neste tempo; mais ainda, considerar a importância que enunciados como "tudo deve ser dito", "tudo deve ser conhecido" teriam alcançado nas práticas pedagógicas atuais (Fischer, 1999) e perceber sua força e sua presença nos "processos de psicologização da vida, constituídos pelos e cons- $\quad$ 3. Acerca do tema, conferir Nikolas Rose $(1998,2007)$. 
tituintes dos processos contemporâneos de governamentalização" (Aquino; Ribeiro, 2009, p. 63).

Seja porque, nessa época, emergiram práticas diferentes, seja porque algumas das práticas existentes enfatizaram-se e articularam-se aos dispositivos de governo que ganharam predominância nas décadas seguintes, tudo parece indicar que, a partir desse momento, as formas de governamento de si promovidas pelos discursos pedagógicos estiveram associadas a dois acontecimentos: as reformas dos sistemas educacionais nos primórdios do século XX - assunto revisado por Popkewitz (2008) e a emergência das chamadas "pedagogias construtivistas" centradas na autoestruturação do sujeito. Esses dois elementos formam parte do desdobramento da forma “liberal” dessa arte de governo que é a “Educação”, formulada pela primeira vez no Emílio, de Rousseau, e retomada posteriormente, a partir dos desenvolvimentos educacionais derivados das teorias evolucionistas, pelos pedagogos da Escola Nova.

Esses dois acontecimentos estiveram atravessados pelos discursos pedagógicos que se fundamentaram na ideia da transformação do indivíduo por sua própria atividade (agência), por meio dos métodos chamados "ativos". Tais métodos podem ser de dois tipos (Not, 2000): de descobrimento por meio da observação - como aqueles que encontramos em Montessori, Decroly e Cousinet -, e de invenção por meio da experiência adaptativa - como foi desenvolvido por Claparède, Dewey, Freinet e Lobrot, entre outros.

Segundo as análises de Walkerdine (1998), o tempo de ênfase nos estudos centrados em métodos ativos foi o mesmo do aparecimento da criança construtivista. Isso significa compreender que se tratou mais da produção discursiva desse sujeito ativo, do que um descobrimento ou reconhecimento que pedagogos e psicólogos fizeram das qualidades e das capacidades presentes no indivíduo humano. Tratou-se

[...] não apenas de estratégias discursivas, de práticas e convenções lingüísticas, mas de uma série de aparatos materiais que fazem "aparecer" a criança construtivista na sala de aula: protocolo de observação; ficha de avaliação; arranjos de mobiliário; disposições arquitetônicas... Mas a natureza construída do sujeito construtivista não teria nenhuma importância não fossem seus efeitos de poder (Walkerdine, 1998, p. 10, grifo do autor).

Aqueles discursos educativos da Modernidade Liberal e, em particular, os discur- 
sos que propunham o reconhecimento de uma particularidade, de uma individualidade do sujeito (correlatos da Psiquiatria e da Psicologia) foram condição de possibilidade para o aparecimento das chamadas pedagogias psi, nos primórdios do século XX. Tratar-se-ia, então, de certa intensificação dessa forma de educação psicologizante, “donatária de um projeto humanista de melhoramento das pessoas e das coisas. Educação que não mais se restringe a remediar danos, voltando-se intensivamente à antevisão dos riscos, a fim de preveni-los” (Aquino; Ribeiro, 2009, p. 65).

Nessas nascentes formas do saber pedagógico, podemos perceber não só a permanência de algumas das práticas de si organizadas na Modernidade Liberal, mas também o ajuste e a emergência de outras, que promoveriam, preparariam e ajeitariam as condições de desenvolvimento das formas de governamento neoliberal começadas a desenhar-se nesse momento. Assim, esse é um tempo no qual se inicia

[...] uma reinscrição de técnicas e formas de saberes, competência, expertises, que são manejáveis por "expertos" e que são úteis tanto para a expansão das formas mais avançadas do capitalismo, quanto para o governo do Estado. Tal reinscrição consiste no deslocamento e na utilização de técnicas de governo que visam fazer com que o Estado siga a lógica da empresa, pois transformar o Estado numa grande empresa é muito mais econômico - rápido, fácil, produtivo, lucrativo (Veiga-Neto, 2000, p. 198, grifo do autor).

Um exemplo interessante das formas que os saberes tomaram no momento de produção dessa criança construtivista, no tempo de constituição desse grupo de experts, foi aquele das discussões em torno do conceito "interesse" e do importante lugar que ele começou a ter nas discussões educativas, nos alvores do século XX (Marín-Díaz, 2009). Assim, por exemplo, em Decroly a ação educativa deve centrar-se nos autênticos interesses da criança. Para o pedagogo e educador belga, a curiosidade e o interesse são duas faces de um mesmo fenômeno psicológico, que manifesta uma necessidade instintiva ou adquirida, ou um sentimento da criança: interesse e curiosidade são signos da necessidade e do instinto e, por isso, é preciso dispor tudo em função de tais necessidades de caráter estritamente físico: sustento, refúgio, proteção e trabalho. Qualquer ação pedagógica teria de levar em conta tanto o "processo natural de desenvolvimento da criança” quanto as "condições do meio onde tal pro- 
cesso ocorre", pois é o estímulo da curiosidade e dos interesses da criança, e não a instrução, o motor da aprendizagem (Decroly; Boon, 1939).

Desse modo, no ato educativo é preciso organizar os conhecimentos de forma global a partir das necessidades vitais e naturais que atraem a curiosidade e o interesse da criança. Antes que manter as crianças em ambientes naturais (como sugeriria Rousseau), em Decroly trata-se de naturalizar os ambientes artificiais (sala de aula, escola), organizando-os com materiais e brinquedos, à maneira de oficinas, que sirvam para estimular a curiosidade e o interesse da criança e, assim, incitar a sua aprendizagem.

Em Claparède, talvez um dos pedagogos do século XX em que melhor se enxerga o atravessamento da Biologia e da nascente Psicologia da inteligência nas discussões educativas, as tendências naturais e as necessidades, físicas e mentais, da criança são consideradas o centro do trabalho pedagógico. Por isso mesmo, ele afirma que toda ação deve centrar-se na atividade da própria criança. A necessidade, ou melhor, a ruptura do equilíbrio físico ou afetivo do organismo, é o motor da conduta do indivíduo e essa conduta tem por função restabelecer e manter o equilíbrio do organismo, o que significa que ela pode se expressar antes ou depois da necessidade - evitando-a ou satisfazendo-a.

Qualquer necessidade sem satisfação produz no indivíduo desequilíbrio, certa tensão fisiológica que, às vezes, também é sentida como tensão afetiva e que se constitui em uma forma de atividade mental, agindo como um mecanismo de proteção, prevendo ou protegendo o organismo de um desequilíbrio. A ação educativa, nessa perspectiva, se constitui no olhar funcional de tais processos mentais e, nela, os problemas da conduta e da aprendizagem são considerados como de adaptação e exigem conhecer as circunstâncias nas quais um indivíduo usa a sua inteligência, para encontrar soluções para eles (Claparède, 2007).

Como podemos perceber nesses dois autores e em outros desse mesmo tempo, tratou-se da emergência de um conjunto de práticas que, vinculadas aos discursos da Psicologia e da Biologia, privilegiaram processos nos quais a criança, suas particularidades e sua própria atividade tornaram-se o eixo da atividade educativa. Tal perspectiva se percebe na ênfase e na importância, nas análises desses autores de noções como interesse, experiência e aprendizagem que estimularam ações “de” e "sobre" os indivíduos, orientadas para esquadrinhar a origem de sua conduta. Para, a partir delas, promover sua transformação não tanto pela ação externa quanto pelo movimento interno do sujeito. 
A aprendizagem, como processo e como resultado da ação educativa, tornou-se um conceito-chave dos discursos pedagógicos durante o século XX. 0 aparecimento e a difusão dessa noção, além de expressar a centralidade que a atividade do indivíduo começou a ter no processo educativo, definiram as bases conceituais da chamada “sociedade da aprendizagem", esse terceiro modo ou forma de ser da sociedade educativa que se organizara a partir do século XVI (Noguera-Ramírez, 2011). Dessa forma, o uso e a difusão do conceito "aprendizagem" tornam-se uma evidência importante da mudança de ênfase que as práticas educativas tiveram, ao orientar-se mais para a atividade do sujeito que aprende do que para os conteúdos ou para os processos de ensino. Tratou-se de uma mudança que significou o ajuste e a articulação de um conjunto de práticas para produzir um sujeito ativo, um sujeito aprendente, esse indivíduo que, por sua própria experiência, por sua própria atividade, aprende o que precisa para viver e ser feliz (Marín-Díaz, 2012).

A ênfase na aprendizagem, no sujeito aprendente, expressa, também, a centralidade que as práticas orientadas para o conhecimento de si, para o saber sobre os próprios interesses e necessidades e assim, para a autoajuda, começaram a ter. Discursos que usaram velhas práticas confessionais e de direção à consciência nas atividades escolares, centrando a atenção do professor em saber mais do aluno, e a atenção do aluno em saber mais de si, dos seus próprios interesses, desejos e necessidades. Contudo, as práticas vinculadas ao conhecimento de si teriam uma crescente aceitação e importância, ao se incorporarem a diferentes esferas da vida social, e fazerem delas espaços de aprendizagem e dos indivíduos, aprendizes permanentes condições centrais no deslocamento da razão governamental liberal para a razão governamental neoliberal.

Nesse sentido, é interessante ver o efeito performativo da governamentalização do social, certa reiteração e circularidade das temáticas usuais no campo educacional, as quais se referem ao cotidiano da vida escolar, mas operam em estreita correlação com formas de governamentalização que "perpassam os muros escolares". Trata-se, como afirmam Aquino e Ribeiro (2009, p. 67, grifo do autor), de processos orientados para a conformação e o refinamento de

[...] tecnologias de si, por meio não apenas da conformação dos gestos dos protagonistas escolares, mas também pela convocação e manipulação de suas motivações profundas. Agora, tratar-se-ia de uma investida diuturna 
direcionada a um controle baseado na probabilidade e gestão dos riscos; controle que visa ao rastreamento contínuo daquilo que tende a escapar das modulações normativas prováveis, absorvendo os desígnios inconfessos das almas dos protagonistas escolares, a modo de intervir em destinos potencialmente funestos.

Em termos gerais, estudar os discursos pedagógicos constituídos nos alvores do século XX e tentar reconhecer os vestígios deles nas temáticas e nas problemáticas educativas atuais, como percebidas pelos autores supracitados, torna possível identificar e descrever a proveniência de algumas das práticas de governo de si (governamento ético), propostas e desenvolvidas pelos discursos educativos desde o começo do século XX, e perceber suas articulações com outras tecnologias que operaram na governamentalidade neoliberal.

Em particular, a emergência da aprendizagem nas teorias e nas práticas psicopedagógicas, no fim do século XIX e nos primórdios do século XX, cumpriu uma dupla tarefa: de uma parte, serviu ou, melhor ainda, permitiu a expansão da forma liberal de governamento baseada na ideia da existência de uma naturalidade no indivíduo, expressa em sua capacidade de agenciamento de si, em seus interesses e em sua liberdade; de outra parte, contribuiu para a emergência dos conceitos de capital humano e competência, estabelecendo, assim, a passagem da forma de governamento liberal para a neoliberal.

O indivíduo aprendente já não é mais aquele indivíduo da identidade que procura seu eu definitivo; pelo contrário, é um permanente exercitante, um unfinished cosmopolita (Popkewitz, 2009) que, como agente, responsável único do seu próprio futuro, está compelido a aprender e a se autoajudar, se quiser atingir o sucesso e, finalmente, a felicidade.

Para concluir, podemos voltar para o início do texto e reafirmar que não há melhor lugar para perceber o funcionamento das práticas de governamento do que nas práticas pedagógicas. 0 filósofo francês não ignorava isso, mas talvez a distância entre os cientistas sociais e os pedagogos franceses tivesse impedido Foucault de se aproximar da produção das ciências da Educação e da Pedagogia. Caso contrário acontece com Sloterdijk, - pensador de uma tradição intelectual na qual a Pedagogia ocupa um lugar-chave dentro das chamadas "ciências do espirito" - que retoma o trabalho que Foucault deixou, redimensionando-o por meio do conceito de "antropotécnicas", 
para o qual resulta evidente o papel das práticas educativas. Daí o lugar que, nas suas reflexões, têm Comenius e a escola como instituição-chave nas técnicas de constituição de humanos na chamada Modernidade. Foi isso mesmo, ainda que em outro registro, aquilo que descobriu Hoskin, professor universitário de uma área distante da Pedagogia, mas que, talvez por sua condição de ensinante e educador, conseguiu perceber a importância das práticas educativas nas transformações das epistemes e dos dispositivos. Não devemos esquecer que foi o professor Foucault ${ }^{4}$ - não o filósofo nem o historiador escritor de livros - quem inventou essa utilíssima ferramenta conceitual que nomeou de "governamentalidade" para encerrar a acolhida e as polêmicas produzidas pelas suas elaborações sobre os dispositivos de saber-poder. Foi nessas aulas, na preparação das suas apresentações para o amplo público que ia escutar suas lições, que o professor construiu essa noção que, novamente, colocou os problemas pedagógicos e educacionais no âmago das suas reflexões. Na verdade, Foucault não foi um "criptoteórico" da Educação; simplesmente, não percebeu o efeito educacional que a Modernidade exercitou no seu pensamento.

4. Uma discussão maior sobre o tema em NogueraRamírez (2008). 


\section{Referências bibliográficas}

AQUINO, Júlio; RIBEIRO, Cintya. Processo de governamentalização e a atualidade educativa: a liberdade como eixo problematizador. Educação e Realidade, Porto Alegre, v. 34, n. 2, p. 58-71, maio/ago. 2009.

BALL, Stephen (Ed.). Foucault and education. Disciplines and Knowledge. London: Routledge, 1990.

CLAPAREDE, Edouard. La educación funcional. Madrid: Biblioteca Nueva, 2007.

DECROLY, Ovide; BOON, Gérard. Iniciación general al método Decroly. Ensayo de aplicación a la escuela primaria. Buenos Aires: Losada, 1939.

ELIAS, Norbert. El proceso de la civilización. Investigaciones sociogenéticas y psicogenéticas. México: Fondo de Cultura Económica, 1987.

FIGUEIREDO, Luis. A invenção do psicológico: quatro séculos de subjetivação (1500 1900). 2. ed. São Paulo: Educ-Escuta, 1994.

FISCHER, Rosa. Foucault e o desejável conhecimento do sujeito. Educação e Realidade, Porto Alegre, v. 24, n. 1, p. 39-59, jan./jun. 1999.

FOUCAULT, Michel. El yo minimalista. Conversaciones con Michel Foucault. Buenos Aires: La Marca, 2003.

FOUCAULT, Michel. Nacimiento de la biopolítica. Curso en el Collège de France (19781979). Tradução de Pons Horacio. Buenos Aires: Fondo de Cultura Económica, 2007.

FOUCAULT, Michel. Nacimiento de la clínica. Arqueología de la mirada médica. Buenos Aires: Siglo XXI, 1985.

FOUCAULT, Michel. Vigilar y castigar. Buenos Aires: Siglo XXI, 2001.

HOSKIN, Keith. Education and Genesis of Disciplinarity: The unexpected reversal. In: MESSER-DAVIDOW, Ellen; SHUMWAY, David; SYLVAN, David. Knowledges: historical and critical studies in disciplinarity. Charlottesville: University Press of Virginia, $1993 a$. p. 271-304.

HOSKIN, Keith. Foucault a examen. El critoteórico de la educación desenmascarado. In: BALL, Stephen (Comp.). Foucault y la Educación. Madrid: Morata, 1993b. p. 33-57. HUNTER, Ian. Repensar la escuela. Subjetividad, burocracia y crítica. Barcelona: Pomares-Corredor, 1998.

LARROSA, Jorge. Tecnologías del yo y educación. Notas sobre la construcción y la mediación pedagógica de la experiencia de si. In: LARROSA, Jorge (Ed.). Escuela, poder y subjetivación. Madrid: La Piqueta, 1995. p. 255-329.

MARÍN-DÍAZ, Dora. Autoajuda e educação: uma genealogia das antropotécnicas contemporâneas. 2012. 310 f. Tese (Doutorado em Educação). Programa de PósGraduação em Educação, Faculdade de Educação, Universidade Federal do Rio Grande do Sul, Porto Alegre. 
MARÍN-DÍAZ, Dora. Infância: discussões contemporâneas, saber pedagógico e governamentalidade. 2009. 191 f. Dissertação (Mestrado em Educação). Programa de Pós-Graduação em Educação, Faculdade de Educação, Universidade Federal do Rio Grande do Sul, Porto Alegre, 2009.

MARÍN-DÍAZ, Dora; NOGUERA-RAMÍREZ, Carlos. Educar es gobernar. La educación como arte de gobierno. Cadernos de Pesquisa, São Paulo, v. 42, n. 145, p. 14-29, jan./ abr. 2012.

NOGUERA-RAMÍREZ, Carlos. Foucault professor. In: REUNIÃO ANUAL DA ANPEd, 31., 2008, Caxambu. Anais... Caxambu: Associação Nacional de Pesquisa e Pós-Graduação em Educação, 2008. 1 CD-ROM.

NOGUERA-RAMÍREZ, Carlos. Pedagogia e governamentalidade: ou da Modernidade como uma sociedade educativa. Belo Horizonte: Autêntica, 2011.

NOT, Louis. Las pedagogías del conocimiento. Bogotá: Fondo de Cultura Económica. 2000.

POPKEWITZ, Thomas. Cosmopolitanism and the Age of School Reform: science, education, and making society by making the child. New York: Routledge, Taylor Francis Group, 2008.

POPKEWITZ, Thomas. Sociedade da Aprendizagem, Cosmopolitismo, Saúde Pública, Prevenção à Criminalidade. Educação e realidade, UFRGS, Porto Alegre, v. 34, n. 2, 2009.

ROSE, Nikolas. Governando a alma: a formação do eu privado. In: SILVA, Tomaz (Org.). Liberdades reguladas. A pedagogia construtivista e outras formas de governo do eu. 2. ed. Petrópolis, RJ: Vozes, 1998. p. 30-45.

ROSE, Nikolas. ¿La muerte de lo social? Re-configuración del territorio de gobierno. Revista Argentina de Sociología, Buenos Aires, ano 5, n. 8, p. 111-150, 2007.

SLOTERDIJK, Peter. Has de cambiar tu vida. Tradução de Pedro Madrigal. Valencia: Pre-textos, 2012.

VEIGA-NETO, Alfredo. Educação e governamentalidade neoliberal: novos dispositivos, novas subjetividades. In: PORTOCARRERO, Vera; CASTELO BRANCO, Guilherme (Org.). Retratos de Foucault. Rio de Janeiro: Nau, 2000. p. 179-217.

WALKERDINE, Valerie. Uma análise foucaultiana da pedagogia construtivista. In: SILVA, Tomaz (Org.). Liberdades reguladas. A pedagogia construtivista e outras formas de governo do eu. 2. ed. Petrópolis, RJ: Vozes, 1998. p. 143-216.

Submetido à avaliação em 8 de janeiro de 2014.

Aprovado para publicação em 11 de junho de 2014. 
